\title{
La presencia de la lengua epigramática de Marcial dentro de la práctica burlesca de las academias del Siglo de Oro
}

The Presence of Martial's Epigrammatic Language

in the Burlesque Poetry of the Academies

of the Golden Age

\author{
Raquel BARRAGÁn AROCHE \\ Centro de Estudios Clásicos, IIFL, Universidad Nacional Autónoma de México \\ raquelbarragan.aroche@gmail.com
}

\begin{abstract}
RESUMEN: En el presente artículo se pretende mostrar un panorama general de la recepción de los epigramas de Marcial dentro de las academias del Siglo de Oro, sobre todo, a partir de una de las características compositivas que el mismo autor llamó la "lengua de los epigramas", elemento que, en distintas épocas, fue un obstáculo para que la obra de Marcial estuviera dentro del canon. No obstante, dentro de la práctica académica del Barroco, la risa adquirió tal importancia que aquella obscenitas comenzó a recuperarse y se convirtió en un pretexto para el ingenio en virtud de que se debía aludir de manera indirecta.
\end{abstract}

\begin{abstract}
This article intends to provide a general overview of the reception of Martial's epigrams in the academies of the Golden Age, especially based on specific characteristics of literary composition that the same author designated as the "language of the epigrams", which, at different times, was an obstacle to the establishment of Matial's work within the canon. However, the laughter acquired such importance within the academic practice of the Baroque that this obscenitas began to recover and became a pretext for ingenuity, which was mentioned in an indirect manner.
\end{abstract}

PALABRAS CLAVE: Marcial, lengua epigramática, academias, recepción, poesía burlesca.

KEY WORDS: Martial, Epigrammatic Language, Academies, Reception, Burlesque Poetry.

RECIBIDO: 27 de febrero de 2015 - ACEPTADO: 5 de junio de 2015.

La recepción de la cultura clásica en el Barroco hispánico no sólo parte de una sed de erudición humanística que da continuidad a la iniciada en el Renacimiento, sino también de la búsqueda de un elemento más básico y próximo a las emociones humanas: el deleite. Trazar la historia de la recepción de textos como los epigramas de Marcial implica plantear, de entrada, la pervivencia de un gusto, que a simple vista parece una afición por lo trivial y lo fácil, pues la risa puede considerarse un efecto estético inmediato. No obstante, en esta premisa se pierde de vista que 
la inmediatez de este efecto conlleva además de la gracia necesaria para hacer reír, una perfección técnica; esto es, un planteamiento retórico y poético que el mismo Marcial defendía en sus dísticos elegíacos. Por un lado, justificaba su interés por este género considerado menor al mostrar la cercanía que su escritura entablaba con el lector y su cotidianidad, mientras que la tragedia y la épica, con sus grandes temas mitológicos, estaban muy lejanas de la realidad. En el conocido epigrama 49 del libro IV, replicaba a aquellos que creían que esta composición sólo consistía en juegos y bromas, frente a la descripción de los temas trágicos que para él no eran más que ampulosidad:

[...] A nostris procul est omnis vesica libellis,

Musa nec insano syrmate nostra tumet.

'Illa tamen laudant omnes, mirantur, adorant' .

Confiteor: laudant illa sed ista legunt. ${ }^{1}$

Por otro lado, esto implicaba un aspecto de la compositio que ponía en evidencia que se podía atraer y mover más al lector - elemento más importante de este proceso, según el poeta bilbilitano- mediante la sencillez y brevedad punzante del epigrama; como se sabe, la 'brevedad' era el rasgo definitorio; Calímaco lo concebía como el ideal de escribir pocos versos (oligostichía), Marcial, de la siguiente manera:

[...] Rara iuvant: primis sic maior gratia pomis, hibernae pretium sic meruere rosae, sic spoliatricem commendat fastus amicam, ianua nec iuvenem semper aperta tenet. ${ }^{2}$

Se presentaba, por tanto, esta estructura in nuce construida por acumulación, repetición o diálogos, aunque la mayoría de las veces sólo se

${ }^{1}$ Mart., 4, 49: "Lejos de nuestros libritos está toda ampulosidad, / y nuestra Musa no se envanece con el extravagante manto trágico. / Sin embargo, todos alaban, admiran y adoran aquellas cosas. / Lo reconozco: las alaban, pero leen éstas”. Las traducciones son nuestras a menos que se indique lo contrario.

${ }^{2}$ Mart., 4, 29: "Lo escaso complace: así hay mayor gracia en los primeros frutos, / así ganan su precio las rosas invernales; / así la altanería hace valer más a la amante despojadora, y no la puerta siempre abierta retiene al mancebo". 
trataba de dos partes, narratio y conclusio: la primera debía crear las expectativas en el lector, y la segunda, como una punta de lanza, debía presentar un cierre con toda la agudeza posible o con lo que la estética griega conocía como aprosdóketon y la latina fulmen in clausula. Con este pinchazo, el lector no podía mantenerse incólume, pues era sorprendido y, en varias ocasiones, herido con aquella acrimonia que se podía perdonar en virtud de que engendraba el placer de la risa; lo cual se lograba formando conceptos mediante el acertado uso de neologismos, coloquialismos, la reductio ad absurdum, analogías, parodias, ironías, aliteraciones, juegos de palabras, ambigüedades entre otros. ${ }^{3}$ En este sentido, hay que notar que esa brevedad punzante, no podía prescindir de la burla - sobre todo en la sátira - , muchas veces creada a partir del vocabulario erótico, pues para Marcial tuvo tal importancia que llegó al punto de considerarla como la misma lengua de los epigramas: realismo lascivo, según él, que podía excusarse porque así habían escrito aquellos que consiguieron ser leídos, como Catulo, Marso, Pedón y Getúlico; ${ }^{4}$ además, aseguraba que sus chanzas respetaban incluso la dignidad de las personas más bajas, pues nunca revelaba sus nombres, y que, en cuanto a él mismo, su vida no tenía nada que ver con la salacidad de su obra, con lo que remitía al tópico: lasciva est nobis pagina, vita proba. ${ }^{5}$ Asimismo, creía que eliminar este aspecto de sus epigramas era equiparable a una castración; esto respondía a quien se quejaba de que sus versos no se podían comentar en la escuela:

Lex haec carminibus data est iocosis

ne possint, nissi pruriant, iuvare.

Quare deposita severitate

parcas lusibus et iocis rogamus

nec castrare velis meos libellos.

Gallo turpius est nihil Priapo. ${ }^{6}$

\footnotetext{
${ }^{3}$ Moreno 2004, pp. IX-LXVI.

${ }^{4}$ Mart., 1, pref.

${ }^{5}$ Mart., 1, 4.

${ }^{6}$ Mart., 1, 35: "Esta es la ley dada a los versos jocosos: / que no pueden gustar, si no resultan picantes. / Por eso, ya que has depuesto tu severidad, / te rogamos que seas permisivo con los chistes y bromas / y que no te empeñes en castrar mis libritos. / Nada hay más repugnante que un Príapo galo".
} 
Casi con la perspectiva de un vidente, Marcial, en éste y otros epigramas, hace una defensa no sólo para su tiempo, sino también para la posteridad; la lengua de sus epigramas, como advierte Vicente Cristóbal, fue el mayor obstáculo con el que a lo largo de la historia se encontró la obra de Marcial para ser aceptada. ${ }^{7}$ Sin duda, no en pocas ocasiones se entendió mal que el explícito lenguaje sexual no hacía más que poner un énfasis en la sátira de lo que él consideraba degradación moral.

Por tanto, si se pone atención en la recepción de la obra, se observará una serie de movimientos que muestran la tipología del horizonte de expectativas, evidentes desde la transmisión textual de las tres familias en las que se agruparon los manuscritos, pues hay casos de censura por omisión o por sustitución eufemística, lo cual muestra que el canon partía de un punto de vista cristiano. ${ }^{8}$ Si espigamos algunos ejemplos, se aclarará la función del epigrama en distintas épocas hasta llegar al Siglo de Oro, que es el periodo que me interesa. Por ejemplo, hay noticia de la presencia de los libros XIII y XIV, Xenia y Apophoreta, en las Etimologías de san Isidoro de Sevilla, en la que dichos epigramas cumplían una función erudita, pues, según Vicente Cristóbal, "facilitaban al enciclopedista una sustanciosa información sobre cuestiones - zoología y agricultura en especial - para su magno compendio". " Sí se conocía a Marcial en las escuelas medievales, pues se estudiaba y se citaba, pero no era muy leído; sin embargo, el gusto por su obra comenzó a resurgir en los siglos VIIII y IX, pues el erudito Alcuino (c. 735-804) y su discípulo Rabano Mauro (776-856) lo citaban, además de que a esta época pertenecieron los manuscritos de la primera familia, que aunque es la más prestigiosa, también es un muestrario de interpolaciones cristianas, y, por ende, del criterio que primaba. ${ }^{10}$

De aquí pasamos al Renacimiento italiano que resulta un puente con la literatura hispánica del Barroco respecto a la revalorización de la obra festiva de Marcial. Claro está, sin dejar de lado el interés erudito, característico de los humanistas italianos. Según Sullivan, Marcial fue uno de los primeros en ser editados en florilegios, ya que aparece en Roma en 1470-1471 impreso por Sweynheym and Pannartz, y en Ferrara en 1471

\footnotetext{
${ }^{7}$ Cristóbal 1987, p. 190.

${ }^{8}$ Montero 1976, p. 345.

${ }^{9}$ Cristóbal 1987, p. 150.

${ }^{10}$ Moreno 2004, p. XLI.
} 
por Andreas Belfort; Después vienen las primeras ediciones comentadas como las de Domizio Calderini (1473) y Georgio Merula (1478), que paradójicamente se editan simultáneamente en 1480, ya que sus autores habían protagonizado una polémica alrededor de la obra de Marcial. No obstante, ya existía un comentario anterior, el del obispo Niccolò Perotti - quien también había tenido una controversia con Calderini, pues los dos enseñaban en Roma la obra de Marcial- editado póstumamente en 1489, porque el autor tuvo pudor de publicarlo por haber incluido los epigramas eróticos, los que, años más tarde, su sobrino, Pirro Perotti, defendería con la siguiente frase: foedum est etiam turpia ignorare. Para 1500 Poliziano y Beroaldo harían útiles contribuciones a la obra de Marcial. No obstante, a esas alturas, se encontraban también voces disidentes y hostiles como la de Volaterranus (Raffaele Maffei), Andrea Navagero y Ludovico da Ponte, quienes rechazaban tajantemente a Marcial por su obscenidad. ${ }^{11}$

Hay que entender que de aquí en adelante el proceso de aceptación o canonización de la obra de Marcial y sus seguidores se desarrolló en ciertos espacios y entre dos corrientes paralelas: la normativa y la referencial. La primera consideraba que la obra de Marcial podía ser fuente de ejercicios retóricos, pero con todo había que ser muy selectivo y prudente, lo cual conllevaba, hasta cierto punto, censura; la segunda, la veía como una posibilidad estética de ser ingenioso y ganarse a los lectores por medio de la risa. Así, en ese primer sentido, aparecieron muchos de los tratados italianos de arte poética, como el de Minturo y Scaligero, que dedicaron especial atención al epigrama, cuya exposición abarcaba distintas modalidades, las cuales se definían a partir de la Antología Planudea, florilegio que fue determinante para el éxito del epigrama como género. ${ }^{12}$ Así pues, aunque las poéticas incluían dentro de los temas el aspecto festivo, se pedía muchas veces la elegancia y propiedad. Esto sucedió también en el ámbito hispánico, pues en preceptivas como la Paraenesis ad politiores litteras adversus grammaticorum vulgum (1529) de Juan Maldonado, representante del humanismo español en tiempos de Carlos V, aunque se reconocía la riqueza de las figuras de dicción, se recomendaba precaución en el uso de algunos autores clásicos - entre ellos Marcial - para el aprendizaje del latín:

\footnotetext{
${ }^{11}$ Sullivan 1991, pp. 265-266.

${ }^{12}$ López Poza 2013, p. 15.
} 
Realmente pondría entre los primeros a Tibulo, Catulo y Propercio, a los que habría que añadir con todo derecho a nuestro Marcial si estuviesen limpios de obscenidades y las cosas honestas no estuviesen mezcladas con las lascivas. Lo mismo pienso de Plauto, Apuleyo y Aulo Gelio, en lo que admiro la abundancia, las figuras de dicción y una imprecisable riqueza oculta. ${ }^{13}$

A principios del siglo XVII, Bernardo de Aldrete, en su tratado Del origen de la Lengua Castellana, repite este mismo argumento al hacer referencia al epigramatista bilbilitano: "Si la descompuesta libertad de este poeta no ofendiera en muchos de sus versos los oídos castos de la piedad cristiana, fuera digno de estimarse entre los mayores vates de aquellos tiempos". ${ }^{14}$ No obstante, la obra de Marcial, ya expurgada, se convirtió en un catálogo de figuras retóricas que sirvió muchas veces a los jesuitas para la enseñanza del latín. Según Sagrario López Poza, tanto en Italia como en España, desde el siglo XVI la práctica del epigrama fue un ejercicio escolar para aprender y fortalecer los conocimientos de oratoria y retórica, pues "por su brevedad, el epigrama se prestaba a ejercicios de traducción del griego al latín, del latín a lenguas vernáculas, y a la práctica de la imitatio". ${ }^{15}$

Este afán de preceptuar su uso denota cuánto se practicó este tipo de composiciones, pues la nómina de autores que usaron la forma epigramática es vasta; no obstante, en la práctica, la norma - o en este caso la censura - sólo fue referencial, pues no se dejó del todo de lado la ya aludida "lengua de los epigramas". Se sabe que entre 1425 y 1426 Antonio Beccadelli publicó su Hermaphroditus, epigramas de contenido sexual imitando a Marcial principalmente, lo cual, además de que le acarreó comentarios adversos, le hizo acreedor de la corona de poeta de manos del emperador Segismundo. ${ }^{16}$ Esto no fue un fenómeno aislado del todo, ya que en el Renacimiento hubo un especial interés por la risa, pues las gracias se veían como una marca de inteligencia entre los miembros que integraban las cortes. Aparecen figuras como Bocaccio (1313-1375), autor de obras en tono erótico burlesco, quien poseyó un manuscrito que contenía el Liber Spectaculorum y los diez primeros

\footnotetext{
${ }^{13}$ Maldonado (1529) 1980, p. 157.

14 Aldrete 1606, p. 113.

${ }^{15}$ López Poza 1999, p. 30.

${ }^{16}$ Montero 2008, p. 10.
} 
libros de epigramas; o como Giovanni Pontano, quien además de preceptuar y componer epigramas, recuperó la importancia de lo risible en el concepto de vir facetus en su obra De Sermone (1509). Camino que también siguió Baldassare de Castiglione en el Cortegiano (1528). ${ }^{17}$ Sin duda, fue el momento propicio para reflexionar sobre la risa, elemento que podía considerarse también ya un arte, pues además aparecen tratados como De ridiculis de Vicenzo Maggi. ${ }^{18}$

Este gusto e interés se desarrolla en un espacio de interacción cortesana, en las llamadas academias de los siglos XVI y XVII. Precisamente ésta fue la vía por la que dichos intereses llegaron a España. Hay que recordar que el virreinato de Nápoles fue uno de los enclaves más importantes que propició el influjo de la literatura italiana. Las academias y tertulias literarias del Barroco hispánico siguieron este modelo de interacción social en la que se privilegiaba el delectare sobre el docere. Por tanto, el ideal renacentista del juego y la risa ${ }^{19}$ se extendió a este periodo en la exacerbación de sentido, lo cual se convierte en la evidencia de que hubo un cambio estético y formal que daría paso a la integración de un nuevo canon.

La historia de las academias españolas es un parámetro que ayuda a medir el panorama documental de las producciones poéticas. Más que otros ámbitos, las academias fueron sensibles a las modas literarias y se convirtieron en una suerte de receptáculos de las tendencias del momento. Los documentos y los testimonios de muchas de las academias se caracterizan por la producción de poesía burlesca, que incluía temas y motivos epigramáticos. La Academia de los Nocturnos de Valencia (1591-1594), considerada la primera en dejar constancia de sus actuaciones, sólo produjo obras de valor estimable en tono festivo, en las que, las más de las veces, se oscilaba entre lo satírico, lo paródico y lo lascivo. ${ }^{20}$

${ }^{17}$ Castiglione en una de sus cartas, en la que solicitaba a Marineo noticias geográficas e históricas de España, preguntaba dónde era Bílbilis, la patria del epigramista Marcial (Menendez y Pelayo 1942, p. XXI).

18 Juan Carlos Pueo 2001.

${ }^{19}$ Este ideal tenía sus fundamentos filosóficos en el pensamiento de Aristóteles: "la diversión es una especie de descanso, y como los hombres no pueden trabajar continuamente, tienen necesidad de descanso" (Arist., EN, X, 1176b, trad. María Araujo y Julián Marías).

${ }^{20}$ Véase Ferri Coll 1998, pp. 327-335. A juicio de José Sánchez (1961, p. 222) y Willard F. King (1963, p. 36), esta academia es una de las más importantes en el Siglo de 
También, los miembros de la Academia de Fuensalida en Toledo (1602 o 1603) - por cuya nómina pasaba el alias del misterioso "Pintor", que parecía designar a El Greco, o el precoz adolescente duque de Estradase dedicaron principalmente a la poesía festiva. La actividad académica en Madrid no estuvo exenta de estas muestras jocosas, de hecho se puede decir que la risa fue uno de sus intereses primordiales; aunque dichas reuniones cambiaban de presidente y de nombre continuamente, siempre albergaron a los grandes ingenios de la época, muchos de los que fueron precursores en las burlas: Lope de Vega, Francisco de Quevedo, Luis de Góngora, Calderón de la Barca, entre los más sobresalientes, ${ }^{21}$ en la Academia del conde de Saldaña que probablemente empezó en 1605, hay noticia de que en sus sesiones Lope compuso sonetos en torno al siguiente tema: "fue el sujeto a una dama, a quien por tener enfermos los ojos mandó un médico que le cortassen los cabellos". ${ }^{22}$ La Academia de Medrano (1617-1622) se suma a este quehacer en los Favores de las musas, recopilación de poemas y comedias escritos por Sebastián Francisco de Medrano, los que son una muestra de los objetivos del grupo que tendía a lo burlesco. ${ }^{23}$ Esta inclinación llega a su plenitud con la Academia de Mendoza (1623-¿1637?), cuyas principales figuras, Pantaleón de Ribera, Gabriel de Corral, Alonso Castillo Solórzano, entre otros, son los responsables de extender esta moda literaria fuera de Madrid.

Por lo visto estas prácticas festivas formaron parte de la mayoría de las academias a lo largo del siglo XVII - Sevilla, Aragón, Valencia y algunas regionales en Córdoba, Argamasilla, Badajoz, Cádiz, Granada, Murcia, Salamanca y Sanlúcar-, a las que habría que añadir las academias de ocasión que tuvieron lugar en Madrid. Entre éstas hay dos que llaman la atención desde el título: "Academia jocosa con que se çelebraron el nacimiento del Excmo. señor Conde de Aliaga, y los años de la Exma. Señora Duquesa de Monte León; dedicada a la Exma. Señora Doña Juana de Aragón, Duquesa de Terranova" y la "Academia burlesca en Buen Retiro a la Majestad Philippo IV el Grande". Los papeles que quedan de la primera - según José Sánchez, fechada a mediados del

Oro español fuera de Madrid, y admiten que, pese a los temas triviales, su producción poética posee atractiva soltura y espontaneidad.

${ }^{21}$ Sánchez 1961, p. 41.

${ }^{22}$ Lope de Vega 1989, t. 3, carta 64, pp. 79-80.

${ }^{23}$ King 1963, p. 53. 
siglo XVII - empiezan con una composición poética - un soneto acróstico- de Francisco Bueno, en donde se adelanta, a modo de advertencia, que los temas consagrados a la duquesa serán "asuntos felices"; y, en efecto, desde la "Carta de Apolo para el secretario de la Academia", pasando por la cedulilla, hasta los asuntos y oraciones, hay apodos, equívocos y títulos irrisorios: "Oraçión jocossa, que dixo un enano", "A un sacristán corcobado que galanteaba una dueña bizca”, entre otros. ${ }^{24}$ En cuanto a la "Academia burlesca en Buen Retiro a la Majestad Philippo IV el Grande”, hay noticia de que se celebró el 20 de Febrero de 1637 para elegir al Emperador Romano. ${ }^{25}$ La burla debía ser de buena ley a partir de temas como: "Un romançe que declare quál estómago es más ymbidiado, el que digiere grandes pesadumbres o grandes çenas", "un romance a una fea, pidiéndole perdón de avella querido", "Seis cançiones de a seis versos a un biejo muy enamorado que espera que a de ser muy favorecido...", entre otros. ${ }^{26}$

En este tipo de espacios se comienza a gestar la práctica de la burla como forma literaria aceptada, en donde las composiciones festivas de Marcial fueron determinantes, ya fuera por los motivos o por la forma epigramática. Lupercio Leonardo Argensola dio cuenta de esto en sus dos discursos sobre las finalidades y objetivos de una academia, escritos entre 1603 y 1610, últimos años del poeta que transcurren en Zaragoza. Como presidente de estas dos sesiones, describió puntualmente en qué debía consistir este tipo de reuniones: se trataba - idealmente- de un aprendizaje y enriquecimiento mutuo entre hombres de armas y de letras - miles doctus - que tenían que dedicar la mayor parte del tiempo a la lectura, estudio y composición de la historia. Entre los textos estudiados que menciona, se infiere que los Epigramas de Marcial eran una de las lecturas obligatorias de las academias, o al menos de ésta: "Mas quisiera yo que no se obligara a leer siempre epigramas de Marcial, aunque es autor agradable y aragonés, porque si no se han de leer (como se han de leer) los deshonestos y obscenos, que, al juicio de los mismos que los

\footnotetext{
${ }^{24}$ Ff. 1r-34v (Mss. 3887 BNE).

${ }^{25}$ Fernando III fue elegido rey de Romanos el 29 de diciembre de 1636. Al siguiente año, Felipe IV organizó actos festivos en honor de su cuñado, y aprovechó dichas festividades para celebrar, a su vez, la victoria de las tropas españolas del año anterior sobre los ejércitos de Francia e Italia, y la llegada de la princesa de Carignano. Véase King 1963, p. 89.
}

${ }^{26}$ Julio 2007, pp. 46-47. 
castraron, son los mejores, muchos dellos son insulsos y sin provecho". ${ }^{27}$ Sin embargo, después de que recomienda la lectura de algunos emblemas de Alciato, concluye: "de manera que no excluyo a Marcial, pero admito otros para variar el gusto". ${ }^{28}$ Esto es evidencia de cuánto gustaba la obra de Marcial, incluyendo aquellos epigramas que para Lupercio eran indignos de imitar, de ahí que en su discurso sugiriera evitarlos. Sin embargo, hay que aclarar que, además del auge del estilo satírico burlesco dentro de las academias, también se escribían epigramas sobre diversos temas. El primer epigrama imitado en lengua española fue el soneto de Garcilaso sobre Hero y Leandro basado en el epigrama 25b del Libro de los Espectáculos, el cual dio pie a una extensa serie e imitaciones (también dentro de las tertulias) sobre éste y otros temas mitológicos, lo que hubiera pesado al mismo Marcial, quien deslindaba sus composiciones de estos ampulosos temas. Aunque, a decir verdad, en algunos epigramas se valió de paráfrasis mitológicas para que la realidad a la que quería aludir fuera potenciada, pero todo a favor de la exaltación de la cotidianeidad.

Por lo demás, a tal grado llegó la importancia de esta forma poética en el siglo XVII que hay noticia de un certamen académico que se celebró con motivo del cumpleaños del serenísimo Baltasar Carlos de Austria, intitulado "Anfiteatro de Felipe el Grande, Rey Católico de las Españas, Monarca Soberano de las Indias de Oriente y Occidente..." (Juan González, Madrid, 1631), en el que sólo se requerían epigramas. La relación quedó a cargo de Joseph Pellicer, quien decidió darle el título de "Anfiteatro" a imitación de Marcial; los poetas debían dar cuenta de la victoria de un toro frente a otras fieras (un oso, un tigre y un león) y de cómo Felipe IV, a su vez, dio muerte a éste con el disparo de un arcabuz. La pelea entre éstas fue un fiasco, pues por más que intentaron provocarlas

${ }^{27}$ Mss. 8755 BNE: 145r-145v. Sobre esto, en el Quijote (II, XVI) hay un pasaje muy ilustrativo (con sesgo irónico), en el que el hidalgo don Diego de Miranda refiere la ocupación de su letrado hijo: "Será de edad de diez ocho años; los seis ha estado en Salamanca, aprendiendo las lenguas latina y griega [...] Todo el día se la pasa en averiguar si dijo bien o mal Homero en tal verso de la Ilíada, si Marcial anduvo deshonesto, o no, en tal epigrama, si han de entender de una manera o otra tales y tales versos de Virgilio. En fin, todas las conversaciones son con los libros de los referidos poetas, y con lo de Horacio, Persio, Juvenal y Tíbulo".

28 También Nebrija incluye dos epigramas (honestos) en el prólogo del Lexicón (1492). Véase González 1992, p. 293, n. 18. 
al combate, ninguna arremetía contra la otra. Pese a esto, entre los que participaron - la mayoría miembros de la academia madrileña- se encontraban poetas consagrados que, a la manera de Marcial, dieron cuenta del suceso: el príncipe de Esquilache, Antonio Hurtado de Mendoza, Lope de Vega, Francisco de Quevedo, Juan de Jáuregui, Gabriel Bocángel, Luis Vélez de Guevara, Pedro Calderón de la Barca, Cristóbal de Salazar Mardones, Antonio de Solís, Francisco de Rojas Zorrilla, Juan Pérez de Montalbán, Juan Ruiz de Alarcón, entre otros.

Marcial ante todo se convirtió en una fuente de ingenio, lo que fue un factor importante para que se considerara un autor canónico, y, por ende, se explotara el aspecto festivo dentro de las academias. Se le consideró príncipe de lo que Baltasar Gracián llamó "agudeza y arte de ingenio", título de su tratado poético, en el que para explicar los diferentes tipos de conceptos, recurrió a los epigramas del "picante Marcial", ${ }^{29}$ traducidos por Francisco Medina y por su gran amigo Manuel de Salinas y Lizana. ${ }^{30}$ La obra contó con 71 epigramas que llevaban este marbete y 50 de los que Gracián indicó que eran traducción o adaptación de un epigrama latino. ${ }^{31}$ También, Francisco Cascales en sus Cartas philológicas tradujo epigramas y escribió 44 en latín dirigidos a Jiménez Patón, advirtiéndole que en ellos había procurado "marcializar aunque si no con su agudeza, con menos lascivia", que aunque era propia de los epigramatarios, no se les concedía a los que profesaban las musas cristianas. ${ }^{32}$

El aprecio por el ingenio y la agudeza de los conceptos, que se promovía en esta y otras preceptivas de la época, no sólo llevó a muchos poetas de academia a marcializar sobre temas satírico burlescos, sino también a hacerlo con "lascivia", valiéndose de alusiones equívocos y dilogías que permitían ocultar el contenido sexual, pero, sobre todo, sorprender mediante las ingeniosas correlaciones con las que formaban conceptos. Por ejemplo, Baltasar del Alcázar, miembro de la Academia sevillana, hizo una reelaboración personal de esta tradición, y prefirió

${ }^{29}$ Gracián 1987, pp. 45 y 85.

30 Sólo menciono a Cascales y a Gracián, pero el epigrama se encontraba en muchas de las preceptivas españolas de los siglos XVI y XVII (López Pinciano, Baltasar de Céspedes, Carvallo, Sánchez de Lima, Rengifo y Herrera), en las que se incluyen las normas generales para definirlo genéricamente. Véase López Poza 2008, pp. 821-833.

${ }^{31}$ López Poza 2013, p. 11.

${ }^{32}$ Cascales 1634, Epístola X. 
dar énfasis a los poemas de contenido lascivo: en ellos dibujó relaciones eróticas, mujeres sexualmente activas y placeres culinarios. De esta línea también desciende Quevedo, asiduo de la Academia madrileña, que en 51 epigramas hizo una traducción - o recreación - de la obra de Marcial, cuya selección se inclinó más por los de temas de dicha índole. Ahora, bien, no sólo basta señalar la adscripción de estos autores a sus sendas academias, sino también que muchos de los epigramas que aparecen en sus obras - y en las de otros autores - nacieron como temas propuestos dentro de aquéllas, ya sea que se supiera porque la rúbrica lo anunciaba o porque los motivos llegaron a ser tan usuales que se reconocía su procedencia en virtud de que varios poetas incluían en sus obras poemas similares. Esto es evidente sobre todo en las novelas académicas, consideradas un muestrario de las actividades que se realizaban dentro de las tertulias, pues entre las composiciones que se engastaban en la trama no podía dejar de haber epigramas y epitafios. Baste de ejemplo la Cintia de Aranjuez de Gabriel de Corral, quien incluyó 64 epigramas casi al inicio de su novela. Además hay que mencionar que muchos de los ahí compuestos presentan coincidencias temáticas con los de las Rimas y prosas de Gabriel Bocángel..$^{33}$

Dentro de las academias se dio un cambio de paradigma en cuanto a la recepción de los epigramas supuestamente deshonestos gracias a la importancia que adquirió la burla como arte de ingenio; la elaboración de éstos se volvió más codiciada, pues requería mayor despliegue de recursos ingeniosos para aludir de manera indirecta a los motivos sexuales. ${ }^{34}$ Por ejemplo, la obra inédita de Pedro Méndez de Loyola - considerado un poeta lascivo en su época- es evidencia de una serie de ejercicios epigramáticos que se requerían dentro de la academia madrileña. Se proponía, entre otras tareas, la confección de dos sonetos, uno dedicado "A una vieja que yendo a hablar, escupió un diente" y otro "A una mujer

33 Willard F. King 1963, p. 118. Sobre la presencia de los epigramas en obras en prosa véase Guillian 1930, pp. 52-111.

${ }^{34}$ En este sentido, hay que mencionar una traducción anónima del siglo XVII, conocida como Marcial en verso castellano, que evidencia este cambio de paradigma, pues los epigramas eróticos se incluyeron porque eran parte del género, pero con la condición de no traducir las palabras deshonestas: [...] Y aunque así queda indecencia, pasará embozada porque no se malogre el donaire del autor, y porque a borrones sueltos que no han de ver emprenta, se les puede permitir mudando las adiciones o dejándolas en su latín, como el de mentula. Bredasola 2008, p. 227. 
muy lasciva en la cama con un hombre". En ambas se incluía una lista de consonantes forzados para construir la rima de los versos. Esta clase de retos ponía en evidencia la búsqueda de las dificultades para mover a risa y admiración; esta era la nueva función que los epigramas adquirieron dentro de las academias. ${ }^{35}$

Finalmente, un testimonio que podría ser considerado como "la admisión" de este tono epigramático se halla en El Rosal (escrito entre 1623-1626) de Rodrigo Fernández de Ribera (1579-1631), quien fue un prolífico escritor de epigramas, muchos de los que se habían atribuido erróneamente a Baltasar del Alcázar; en la introducción a su obra epigramática proclama a Marcial como el único modelo que los poetas burlescos debían imitar:

[...] ¡Ó padre Marçial, emulaçión de los Catulos, Jubenales y Persios, y vosotros, ó hermanos poetas y hijos de aquel padre en este estilo! ¡Aquí del Pegaso, que si él fue buen cavallo, español sería! Y sin duda que fue bueno, que a lo menos las alas esençia fueron del Zéfiro, de quien se enpreñaban las yeguas. [...] Y de los prados del Betis, vosotros digo que [...] con la vrebe bala de una redondilla derribáis de desautorizada rissa la más mesurada muralla de una frunçida beata. ${ }^{36}$

Más allá del acendrado nacionalismo, se pone de relieve que al mencionar a Marcial como emulación de los "Catulos", hay una asimilación explícita de las composiciones de tipo lascivo, pues muchos de los carmina y de los epigrammata de Catulo tenían un manifiesto contenido sexual; éstos, por tanto, quedaban al mismo nivel de las sátiras de los "Persios" y "Juvenales" en la amplia gama de códigos con los que se componían los epigramas.

Se puede decir que las tres características que siempre defendió Marcial de su obra: la brevedad, la agudeza y la lengua de los epigramas, finalmente, hallaron terreno fértil dentro de las academias del siglo XVII. En este espacio, de alguna manera, se cerró esta suerte de triángulo que definía genéricamente a los epigramas del poeta bilbilitano. Quizá se deba al hecho de que como un simple ejercicio representaba un reto que

35 Por cuestiones de tiempo y espacio, sólo he mencionado a algunos autores, pues este trabajo es parte de una investigación más extensa, en la que se ampliará el panorama.

${ }^{36}$ Lara 1992, p. 70. 
daba pie a la variatio o una suerte de reescritura casi infinita, de ahí que se quisiera explotar también este lado del género; la lengua epigramática, junto con la burla, representaba un pretexto para componer ingeniosas poesías que, no es casualidad, se gestaban en los espacios cerrados de las tertulias académicas, aunque posteriormente salieran a la luz en algunas de sus obras. Es un hecho que el horizonte de expectativas era otro y Marcial se acogió como esa figura de autoridad que podía legitimar la escritura de aquellos poetas que querían dedicar su ingenio a engendrar el deleite y la risa en los lectores. La norma seguía en pie, pero la lengua epigramática encontró un resquicio por medio del arte de la risa.

\section{BIBLIOGRAFÍA}

AldRETE, Bernardo, Del origen de la Lengua Castellana, Roma, Carlo Willieto, 1606.

Aristóteles, Ética a Nicómaco, trad. María Araujo y Julián Marías, Madrid, Centro de Estudios Constitucionales, 1999.

Bredasola, Andrea (ed.), Marcial en verso castellano, Pavía, Ibis, 2008.

Cascales, Francisco, Cartas filológicas, Murcia, Luis Verós, 1634. Disponible en http://www.cervantesvirtual.com/obra-visor/cartas-filologicas--0/html/fef8ba6a-82b1-11df-acc7-002185ce6064_18.html\#I_1_, 3 de octubre de 2014.

CRISTÓBAL, Vicente, "Marcial en la literatura española", en Actas del Simposio sobre Marco Valerio Marcial poeta de Bilbilis y de Roma II, España, Diputación Provincial de Zaragoza-UNED, 1987, pp. 149-209.

FERri Coll, José María, "Burlas y chanzas en las academias literarias del Siglo de Oro: los Nocturnos de Valencia”, en Florencio Sevilla y Carlos Alvar (eds.), Actas del XIII Congreso de la Asociación Internacional de Hispanistas, Madrid, Castalia, 1998, pp. 327-335.

GonZÁlez CAÑAL, Rafael, "Marcial y el conde Rebolledo: versiones áureas de seis epigramas latinos", en Cuadernos de Filología Clásica II, 1992, pp. 289-305.

Gracián y Morales, Baltasar, Agudeza y arte de ingenio, 2 vols., ed., introd. y nts. Evaristo Correa Calderón, Madrid, Castalia, 1987.

Julio, María Teresa (ed.), Academia burlesca que se hizo en Buen Retiro a la majestad de Filipo cuarto el Grande, Madrid, Universidad de Navarra-Iberoamericana-Vervuert, 2007.

KING, Willard F., Prosa novelística y academias literarias en el siglo XVII, Madrid, Silverio Aguirre Torre, 1963.

LARA GARRIDO, José. “El Rosal, cancionero epigramático de Rodrigo Fernández de Ribera: edición y estudio del Ms. 17524 de la Biblioteca Nacional de Madrid (con algunos excursos sobre problemas de transmisión y edición de las poesías de Baltasar de Alcázar) I", en Voz y Letra, 2, 1992, pp. 23-78. 
LÓPEZ POZA, Sagrario, "Luis de Góngora en la trayectoria aureosecular del epigrama”, en Góngora y el epigrama. Estudio sobre las décimas, Juan Matas Caballero, José María Micó y Jesús Ponce Cárdenas (eds.), Madrid, Iberoamericana / Universidad de Navarra / Vervuert, 2013, pp. 9-42.

-, "El epigrama en la literatura emblemática española", Analecta Malacitana, XXII, 1999, pp. 27-55.

—, "El epitafio como modalidad epigramática en el Siglo de Oro (con ejemplos de Quevedo y Lope de Vega)", en Bulletin of Hispanic Studies, LXXXV, 2008, pp. 821-833.

"Lupercio Leonardo de Argensola en la Academia de Zaragoza", en Libro de varias cosas en prosa, de hombres insignes en letras y política, tomo primero, Mss. 8755 BNE.

Maldonado, Juan, "Paranaenesis ad literas", en Eugenio Asensio y Juan Alcina Rovira (eds.), Juan Maldonado y el humanismo español en tiempo de Carlos $V$, Madrid, Fundación Universitaria Española, 1980.

MARCIAL, Epigramas, 2 vols., trad. Enrique Montero Cartelle, Madrid, Alma Mater, 2014.

MenÉndeZ y Pelayo, Marcelino, "Introducción", en Baldassar Castiglione, El cortesano, trad. Juan Boscán, Madrid, Consejo Superior de Investigaciones Científicas, 1942.

Montero, Cartelle Enrique, "Censura y transmisión textual en Marcial", Eclás, XX, 1976, pp. 343-352.

- , "Estudio preliminar", en Antonio Beccadelli, Hermafrodito, Madrid, Akal, 2008.

Moreno Soldevilla, Rosario, "Introducción", en Marcial, Epigramas, Madrid, Alma Mater, 2014.

Pueo, Juan Carlos, Ridens et Ridiculus: Vicenzo Maggi y la teoría humanista de la risa, Zaragoza, Anexos de Tropelías, 2001.

SÁncheZ, José, Academias literarias del Siglo de Oro español, Madrid, Gredos, 1961.

Sullivan, J. P., Martial: The Unexpected Classic. A Literary and Historical Study, Cambridge, Cambridge University Press, 1991.

VeGA, Lope de, Epistolario de Lope de Vega Carpio, 3 vols., Agustín González de Amezúa (ed.), Madrid, Real Academia Española, 1989. 
